Supplement of Hydrol. Earth Syst. Sci., 21, 4259-4282, 2017

https://doi.org/10.5194/hess-21-4259-2017-supplement

(c) Author(s) 2017. This work is distributed under

the Creative Commons Attribution 3.0 License.

(c) (1)

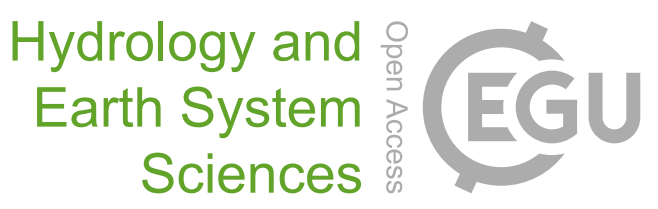

Supplement of

\title{
A method to employ the spatial organization of catchments into semi-distributed rainfall-runoff models
}

Henning Oppel and Andreas Schumann

Correspondence to: Henning Oppel (henning.oppel@rub.de)

The copyright of individual parts of the supplement might differ from the CC BY 3.0 License. 


\section{S1 Application of ACS on hydraulic conductivity}

As stated in the main publication we identified surface-slope values or rather its fragmented small scale, yet equally distributed, heterogeneity as cause of reduced performance values of the ACS-algorithm. As a consequence we concluded that characteristic offering wide-range patterns like pore volume are better to assess by the algorithm. Since we only analysed two characteristics we have to introduce a third application to prove our conclusions.

As mentioned in the data section (Sect. 2) we can use data of hydraulic conductivity (HC) as our third variable. The data (shown in Fig. S1) is like pore volume extracted from soil and vegetation maps via pedo-transfer functions and only available for Main, Mulde and Regen.

Sub-basins and zones, as well as distance-factor functions of standard deviations for separated and the unseparated basin are shown in Fig. S2. Table S1 gives the performance values $\alpha_{1}$ and $\alpha_{2}$. Results show that the application brought comparable outcome to the results obtained for pore volume and slope. Total reduction is similar to the success rates for pore volume in a range between $45 \%$ and $59 \%$. But the remaining variance is especially for the Regen and Main catchment remarkably low, nearly no variance is left above the threshold. Also the Mulde application led to a significant reduction, though $23 \%$ remain above the threshold.

Causes for the outcome comply with our conclusions in the main publication: clearly visible in the distance-factor functions (Fig. S2) and on the maps (Fig. S1) are soil enclosures in the Mulde (close to the outlet) and Main (centre) basin.

This complementary case study on HC does yield new discoveries, yet it approves our conclusions and our assessment of applicability. 
Table 1: Results of applications of $A C S$. Number of ascertained sub-basins, normalized reduction of standard deviation and density of close to stream zones.

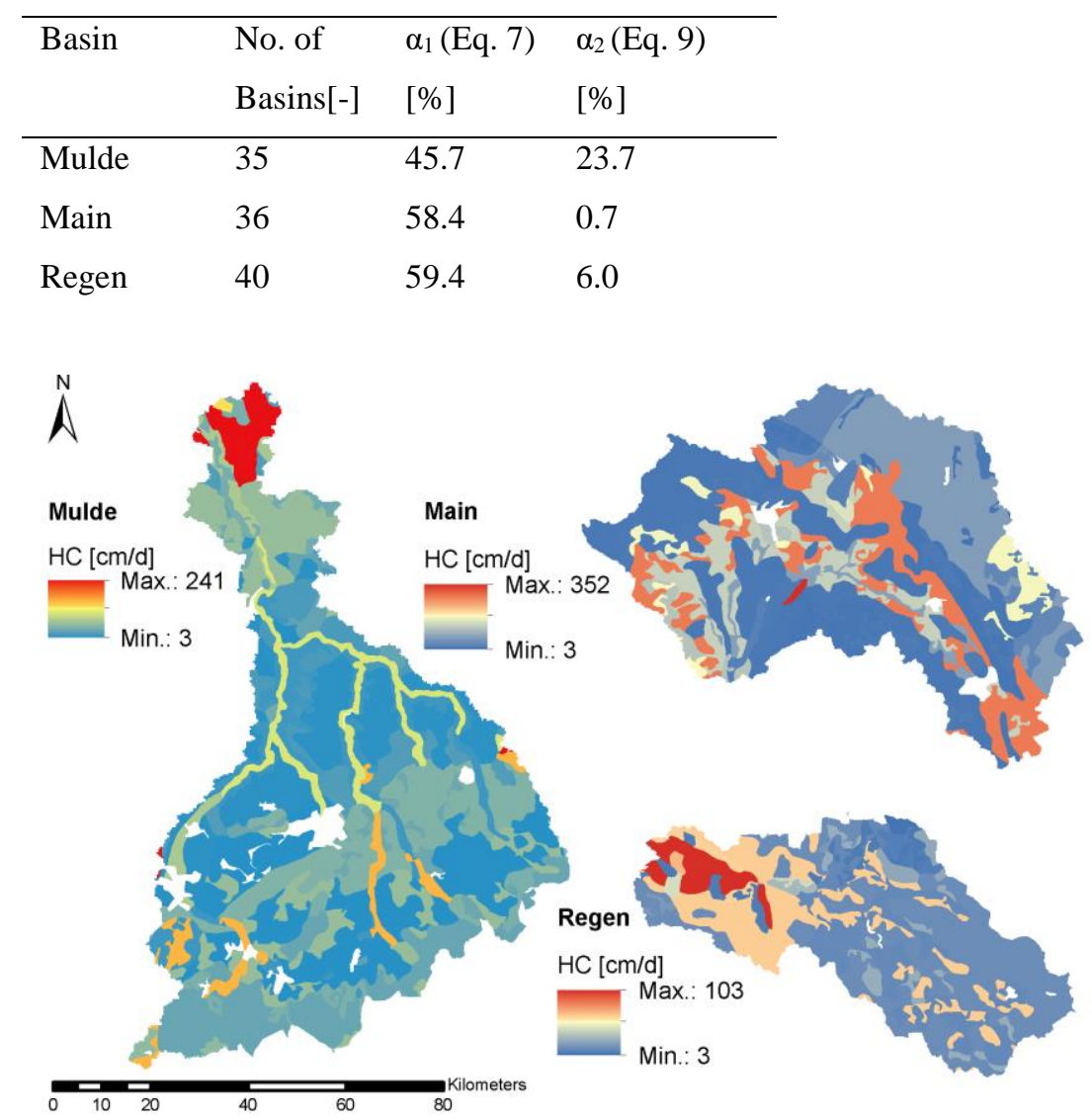

Figure S1: Hydraulic conductivity in the Mulde (left), Main (upper right) and Regen basin (lower right)
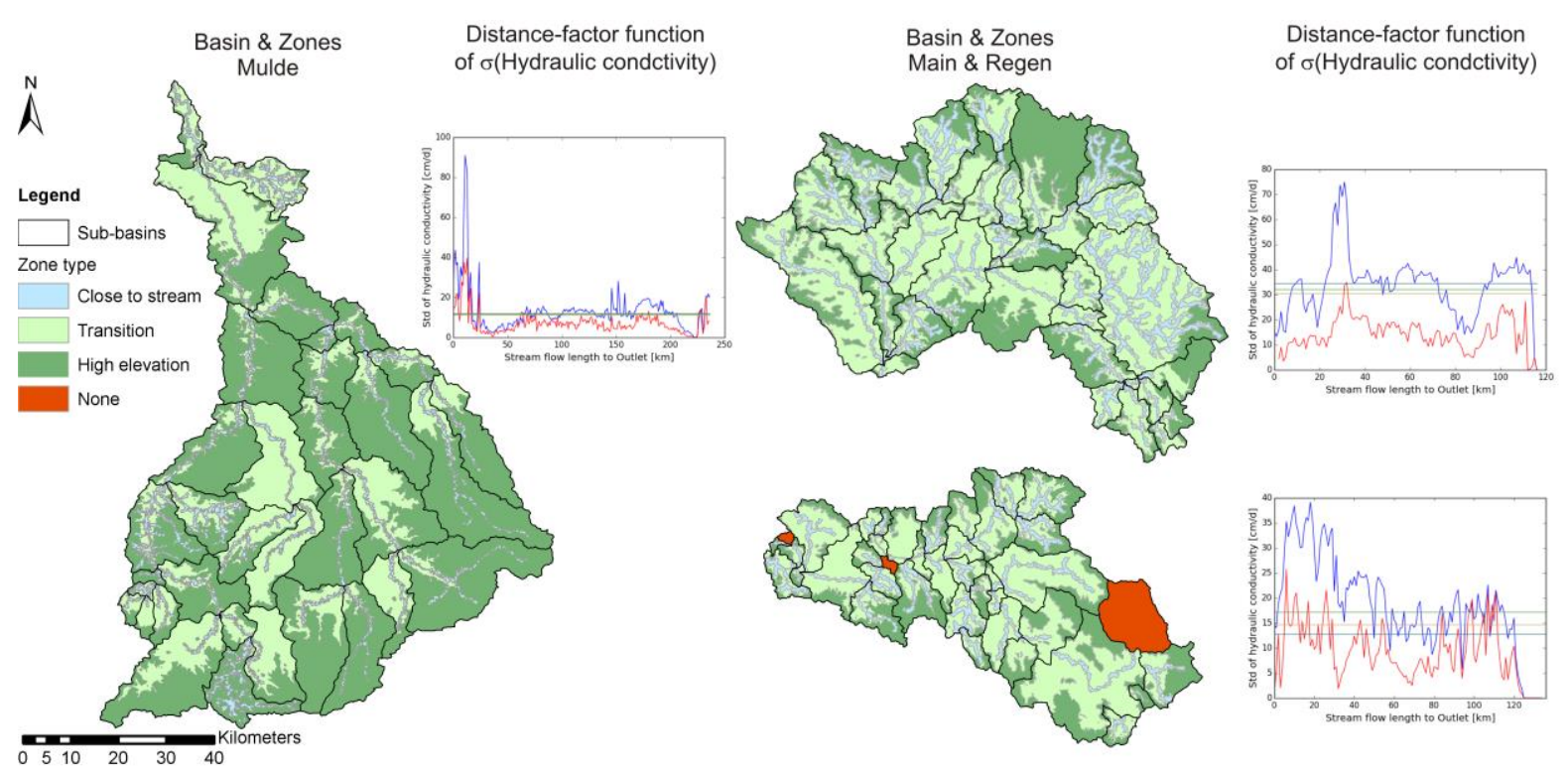

Figure S2: Results of ACS application for catchments of the Mulde, Main and Regen, sub-basins based on $\mathrm{HC}$. Comparison of $\sigma v(C)$ and $\sigma s(C)$ for each application (red and blue lines). 